\title{
Is Private Production of Hospital Services Cheaper than Public \\ Production? A Meta-Regression of Public versus Private Costs and Efficiency for Hospitals
}

\author{
Germà Bel \& Marc Esteve \\ (Forthcoming International Public Management Journal)
}

\begin{abstract}
The question of whether private organizations can outperform public ones in public service delivery has been a major topic of interest over the last few decades. However, the empirical evidence does not systematically support the hypothesis of lower costs and higher efficiency when private organizations deliver public services. To better understand the cost and efficiency differences between public and private organizations, we have conducted a metaregression analysis of econometric studies relating to hospital ownership and performance. We have analyzed 61 estimates extracted from health studies, using public versus private hospital costs and efficiency as an independent variable. Our analysis shows a genuine true effect in favor of public sector hospitals. Although we found evidence that the public sector may provide public health services more cheaply than the private sector, the latter achieves better productive efficiency. We discuss how this divergence in results is affected by factors such as country, year, the use of panel data in a study, the extent to which performance is measured by examining financial costs, and the inclusion of not-for-profit hospitals.
\end{abstract}




\section{Is Private Production of Hospital Services Cheaper than Public \\ Production? A Meta-Regression of Public versus Private Costs and Efficiency for Hospitals}

\section{INTRODUCTION}

How does ownership influence organizational performance? Academic interest in the study of public and private sector differences has been justified as a means of exporting the most efficient management techniques from each sector to its counterpart (Box 1999; Boyne 2002), and, more broadly, to justify the participation of private organizations in the provision of public services (Hodge 2000). According to Stiglitz, the distinction between the public and private sectors must be understood by differentiating between those responsible for producing, providing, and paying for the service (2000). Over recent decades, the underlying logic has suggested that allowing private organizations to participate in providing public services will increase service performance (Boyne et al. 2003; Pollitt \& Bouckaert 2011). Scholars have made multiple attempts to test this assumption and assess the effects of ownership on service performance (Boyne 1998, 2002; Hodge 2000; Bel \& Warner 2008; Bel et al. 2010; Basu et al. 2012). However, as Walker et al. (2013) have pointed out, the empirical evidence of differences in performance between public and private ownership remains ambiguous.

One of the main reasons why these comparisons have been so challenging is the very conceptualization of the term "performance." Walker et al. (2010) have acknowledged the multidimensionality of performance and the resulting operational challenges that arise when it must be measured. In their view, performance includes quality, efficiency, effectiveness, equity, probity, and responsiveness in delivering a public service. The literature has tried to overcome this challenge by focusing on cost savings when comparing the two sectors. 
Examples include the descriptive meta-analyses of Boyne (1998), Hirsh (1995), and Hodge (2000), which failed to support the hypothesis that the private sector can provide public services more cheaply. Bel et al. (2010) were able to perform a meta-regression of costs and ownership for municipal-level solid waste and water services. Interestingly, although they did not find an empirical genuine effect of cost savings resulting from ownership, they did find important differences when comparing water and solid waste management. Bel et al. (2010) argue that this can be explained by the degree of market competition. In the solid waste sector, where potential for competition is relatively high, studies rely on cost data; by contrast, competition is very weak in the urban water sector. The available data relate more frequently to technical inputs and outputs than to financial costs [data on levels of competition in all sectors mentioned in this paragraph have been obtained from Hefetz and Warner (2012)]. Unlike Bel et al. (2010), the present study focuses on one sector only: health services.

When analyzing the relationship between ownership and performance, health services constitute a particularly interesting sector, as they are strongly regulated, with low potential for competition. Goddard (2015) considers this to be true for the entire global health sector; even in countries like the United States, where multiple organizations offer health services, there is no real market competition. This situation is a consequence of two main factors. First, the individuals making choices are heavily affected by information asymmetries because they do not have enough medical knowledge to assess their own conditions; in other words, people generally choose a health service before finding out what medical issues they have. Second, their choices are typically restricted to the options made available by their health insurance providers. Hence, market rules apply more to the competition among health insurance providers than to any competition between hospitals or primary health centers. The fact that empirical studies of this sector have focused both on financial and cost data and also on 
technical data (a substantial sample of studies in each case) provides further insights, complementing the existing literature.

A second major argument in favor of allowing the private sector to participate in delivering public services is the view that this increases service efficiency (Andrews \& Entwistle 2013; Haque 2001). In other words, the issue is not just whether the service is cheaper, but also whether the division of inputs and outputs produces more favorable results when private actors provide the service. The economic theory of property rights offers a possible explanation: in the private sector, managers and owners have a direct financial incentive to increase efficiency; this is not the case in public organizations, where property rights are not linked to employee salaries (Andrews et al. 2011; Wamsley \& Zald 1973).

While the literature is rich in analyses of the relationship between ownership and service costs (Boyne 1998; Hirsh 1995; Hodge 2000; Bel et al. 2010), there is little empirical evidence of the effects of ownership on efficiency. This issue is important, as the costs paid by users and governments in highly regulated sectors do not necessary reflect productive efficiency (Vickers \& Yarrow 1991). Andrews et al. (2011) have examined the overall relationship between publicness and performance, concluding that there is mixed evidence of an ownership effect on service efficiency, and that future studies are needed to examine this topic further. The present study answers this call. It makes an important contribution to the literature by comparing sector differences - assessing the extent to which public and private organizations incur different levels of cost and efficiency when providing public services. It also explores the factors that account for these differences. The present study moves beyond conceptualizing performance as simply a function of savings to include the concept of efficiency. It does so by analyzing the reasons why previous studies have obtained different results when comparing the service costs of public and private hospitals. A meta-regression 
analysis of all econometric studies of health-service production costs is used to produce empirical evidence. We analyse 61 estimations extracted from over 16 health studies, using hospital costs as a dependent variable. Our analysis identifies the factors that drive contrasting results in the empirical literature, in relation to the cost of delivering health services through public versus private organizations.

\section{THEORETICAL BACKGROUND OF THE RELATIONSHIP BETWEEN OWNERSHIP AND COSTS}

The study of public and private sector differences has provided some compelling comparisons in both sectors (see, for example, the seminal work of Rainey, Backoff, \& Levine 1976 and Perry \& Rainey 1988). However, the need to define public and private organizations has led to very different theoretical and epistemological approaches. The literature differentiates between three overarching points of view ${ }^{1}$ : the generic approach, the core approach, and the dimensional or "publicness" approach (Bozeman \& Bretschneider 1994; Scott \& Falcone 1998).

The generic approach acknowledges that, although some differences can be found when comparing public and private sectors, the core dimensions of management share many similarities, as managers must do similar things in similar ways (Murray 1975; Chandler 1991). The generic approach argues that organizations are not affected as much by their publicness or privateness as by other variables, such as organizational size and the degree of centralization and formalization present in any organization (Scott \& Falcone 1998). Because of that, the generic approach dismisses classifications based on public-private differences, claiming that it is overly simplistic to argue that private sector organizations are mainly driven by monetary

\footnotetext{
${ }^{1}$ Other authors have identified five main approaches to the public/private distinction: generic, economic core, political core, normative, and dimensional (see Pesch 2008 for a full description).
} 
profit. This approach suggests that "management functions, organizational processes, and managerial values are essentially identical across sectoral boundaries“ (Ibid., p. 127).

By contrast, the core approach makes a clear distinction between public and private organizations, focusing mainly on the legal distinction: publicly owned versus privately owned. This approach can be described from an economic perspective-differentiating between the state and the market - or from a political perspective - emphasizing the political influences to which public organizations are subject (Pesch 2008). Ownership of the property rights to the residual benefits of an activity becomes a key factor in determining whether an organization is public or private (Vickers \& Yarrow 1988, 1991). Relatedly, public choice theorists (i.e. Niskanen 1971: Tullock 1965) have suggested that public sector organizations operate without market pressures and therefore cannot use market-provided information for their own benefit, as a performance indicator. Instead, they rely on political will and budgetary changes to set their production levels. Although the core approach is often adopted in the public administration literature, some authors have argued that reality undermines its basic distinction, given the large array of hybrid organizations that cannot be adequately described using a classic public versus private distinction (Bozeman \& Bretschneider 1994).

The third point of view, the dimensional or "publicness approach" (Bozeman 1987), builds upon the notion that "publicness is not a single, discrete attribute; rather, organizations (government, business, hybrid) are more or less public, depending on the extent to which externally imposed political authority affects them“ (Bozeman \& Bretschneider 1994). From this perspective, the dichotomy between public and private ownership is not what differentiates organizations, but rather their interaction with a set of dimensions, such as funding, aim, or a final product or service. One of the main theoretical precursors of the dimensional approach is Wamsley and Zald's (1973) study, which argues that public and private organizations should 
be seen as the result of two main variables: polity and economy. "Polity" refers to activities and behaviors that relate to the development of agency purpose (such as forced recruitment and socialization, or monitoring the environment). "Economy" denotes actions that help to accomplish a particular task effectively (such as resource allocation, or division of labor). Accordingly, publicness is seen as a continuum, rather than a dichotomy (Bozeman 1987).

To test the three approaches, Scott and Falcone (1998) verified their explanatory capacity and concluded that, although all explained some characteristics of organizations, the core and dimensional approaches had more explanatory power than the generic approach. Their empirical evidence supports the idea that public and private organizations are different, justifying the study of public/private differences in relation to service performance (Scott \& Falcone 1998).

Given the long-standing discussions about the differences between public and private organizations, it is not surprising that several authors have focused on the question of whether public organizations can outperform their private counterparts, and vice versa (Andrews et al. 2011). As far as we know, the first empirical multivariate tests comparing public and private organizations that provided public services were carried out by Hirsch (1965) in the field of solid-waste collection; he found no significant cost difference between public and private production. The model proposed by Hirsch (1965) was, with minor modifications, used in subsequent studies by Kitchen (1976) in Canada, Kemper and Quigley (1976) and Collins and Downes (1977) in the US, and Pommerehne and Frey (1977) in Switzerland. Apart from Collins and Downes (1977), all reported that private organizations outperformed public ones. In a similar vein, Mann and Mikesell's (1976) multivariate empirical study compared public and private performance in the water distribution sector and found that public production was more efficient. 
Interestingly, several years after these initial studies, two review studies [one a literary review (Bel \& Warner 2008) and the other a meta-regression analysis (Bel et al. 2010)] assessed ownership effects on water and solid-waste production. These authors found no systematic support for lower costs with private production; instead, they found that the analytical time period and contextual factors, such as service characteristics and policy environments, explained various performance differences. In the same vein, Carvalho et al. (2012) conducted a meta-regression to compare public and private production of public services in scale and scope economies. A recent comprehensive and systematic review of the international literature on "contracting out" in the technical and social services found no evidence of differing costs between public and private providers of social services, including healthcare (Petersen et al. 2018).

These differences indicate that ownership has no clear impact on performance. Instead, as Andrews et al. (2012) have warned, performance is very context-dependent and should be studied within a single service. With this in mind, the next section addresses the issue of public versus private performance in a particular service: public and private hospitals.

\section{Assessing Public and Private Performance in the Health Sector}

Over the last few decades, numerous studies have analyzed performance differences in the healthcare sector between public and private hospitals. Campbell (1990) wrote a seminal work, launching this line of research. Her study of 224 US hospitals found that publicly owned hospitals were significantly less efficient than privately owned ones. A subsequent study by Chirikos and Sear (1994) of US hospitals refined the empirical approach by providing a DEA analysis to account for six years of data (1982-1988). In comparing public and private hospital performance, the authors found that private hospitals had slightly higher technical efficiency. They argued that the net efficiency advantage of for-profit hospitals was very small - at the 
borderline of statistical significance $(p=.06)$. Their results have been supported by other studies of US hospitals, which have revealed that public hospitals are less efficient than forprofit hospitals (Vitaliano \& Toren 1996).

Fournier and Mitchell (1997) have argued that ownership has little effect on performance. According to their results, the factor that strongly impacts a hospital's efficiency is not its public or private status, but whether it belongs to a large group of hospitals - known as a multiservice system. Despite an initial agreement that public hospitals could be less efficient than privately owned hospitals, different results began to emerge as more authors analyzed the topic. Rosko (1999) carried out a study of US hospitals with a very large $n(3,262)$. Challenging previous results, he found that for-profit hospitals tended to be less efficient than not-for-profit ones. He argued that this could be explained by the tendency of private hospital directors to focus on value leadership, aiming to provide the best possible services, regardless of cost (Ibid.). As the author states "the implementation of value leadership requires hospitals to differentiate themselves so purchasers will be willing to pay more for their services (Rosko, 199, p. 71). In the same vain, a more recent study of US hospital performance (including ownership as an explanatory variable) revealed a similar pattern. Using a stochastic frontier model of hospital technical efficiency, Brown (2003) has reported higher inefficiencies in private hospitals than in public ones. Arguably, this could be explained because "for-profits may trade-off efficiency, in terms of output, for less congestion and possibly higher quality" (Brown, 2003, p. 157).

Although the literature on this topic is heavily dominated by US studies, researchers have made a few attempts to address this issue in other national contexts. Authors have also addressed the performance differences in public and private hospitals in other countries. Bosmans and Fecher (1995), for instance, have provided an interesting cross-sector analysis of 
Belgian hospitals, finding that publicly owned hospitals were more efficient, on average, than private ones. Two further studies have disentangled the relationship between ownership and performance in European hospitals, obtaining different results. Herr's (2008) study of German hospitals provided empirical evidence that publicly owned organizations were more efficient than privately owned ones. However, a few years later, she developed a second study (also in Germany) that reported no significant differences in cost efficiency, despite revealing higher profit efficiency in private hospitals (Herr et al. 2011). This research issue has also been explored in the Asian context, for example in a study of Taiwanese hospitals developed by Lin et al. (2005). By analyzing data from Taiwan National Health Insurance Research, these authors concluded that publicly owned hospitals experience higher costs per patient than privately owned ones.

Interestingly, two meta-reviews of ownership and performance obtained opposite results, despite being developed by the very same authors. Shen et al. (2007) reviewed papers linking ownership and performance for the period between 1990 and 2004. In their results, the authors explained that ownership had a strong influence on performance, although private hospitals did not appear to perform better than public ones. A comprehensive review conducted by the Australian Government Productivity Commission likewise found no cost differences between public and private hospitals (Productivity Commission 2009).

In a nutshell, although a wide array of studies have explored the relationship between ownership and hospital performance, their evidence points to mixed results. The extent to which ownership influences performance has not been clarified within the current literature. The present study argues that one reason for these mixed results within the literature on organizational performance is the very definition of organizational performance. In this study, organizational performance considers both the costs that the service passes to the user, not for 
the organization producing the service, and the efficiency of the hospital, which reflects the production costs of a particular service.

\section{Theoretical Expectations}

Nowadays, there is no empirical consensus on the question of whether public services perform better than private ones. Although many studies have found that private outperforms public, a considerable number of studies have reported the opposite (see, for a review, Bel et al. 2010). Hence, we cannot provide an a priori proposition that the public sector will have lower or higher costs than the private sector when delivering health services.

The industrial organization literature focuses on the role of productive efficiency (related to the concept of technical efficiency: optimality in combining outputs and inputs) when analyzing public versus private delivery of public services. From this perspective, the high management restrictions faced by public managers should ensure that private service delivery is the lower-cost option. In their seminal study of privatization in the UK, Kay and Thompson (1986) have argued that the main reason private sector organizations are expected to outperform their public counterparts is "the constraints and opportunities with which that management is faced“ (Kay \& Thompson 1986, p. 19). A high level of regulation or a lack of market competition will reduce the difference between public and private organizations, because the private sector no longer benefits from extra managerial room to maneuver. Likewise, Bel et al. (2010) have drawn on property-rights theory to argue that "ownership is an important factor because it confers the right to obtain benefits from actions related to assets, such as profit, as well as the benefits of innovation and efficiency gains. Bureaucrats have control rights under public ownership, but they do not enjoy property rights and thus cannot directly benefit from the profits generated by cost reduction“ (Bel et al. 2010, p. 556). When the productive efficiency of public and private service delivery are compared from these 
theoretical perspectives, the private sector can be expected to produce better results than the public sector.

However, when considering organizational performance, a second major issue is the concept of allocative efficiency, which differs from productive efficiency. According to Kay and Thompson (1986, p. 20), "Productive efficiency requires that whatever is done should be achieved at minimum cost; allocative efficiency implies that what is done meets consumer needs at prices which reflect the costs of provision." When productive efficiency does not translate into allocative efficiency, users may fail to benefit from productive efficiency in the service. Some sectors suffer from competition failures; in the health services, the service costs paid by users rarely reflect the actual production costs incurred by the organization delivering the service. Hence, while competitive markets tend to force the private sector to search for productive efficiency and to deliver allocative efficiency (Kay \& Thompson, 1986), this may not be the case when a private organization produces a public service in a sector with low levels of competition and tight regulation. Lacking market discipline because of weak competition, allocative efficiency is unlikely to be achieved in the marketplace; however, government regulation (through contracts or public production) can help users benefit from and improve productive efficiency. Allocative efficiency has a stronger relationship with service costs, while productive efficiency is measured by analyzing the physical relationship between outputs and inputs. Accordingly, any comparison of financial costs in the public and private arenas is likely to favor the public sector, to the detriment of private organizations.

A third and final variable, of particular importance when considering cost differences in service delivery, is the potential inclusion of private not-for-profit organizations in the public-versus-private analysis. Not-for-profit organizations are member-based institutions, not owned by groups of shareholders or investors, (Rosenau \& Linder 2003). In practice, this 
means that they can belong to non-governmental organizations, specific communities or-in the case of hospitals — religious organizations or health authorities (Herrera et al. 2014). Unlike for-profit private organizations, not-for-profit organizations do not distribute their surplus funds to those who control them. This money is either reinvested in the organization or used to establish related institutions or projects. Arguably then, while for-profit organizations seek high economic returns when delivering a service, not-for-profit organizations work to maintain economic sustainability to deliver the service (Gray 1986). From a theoretical point of view, not-for-profit organizations delivering public services can be expected to incur higher costs than their for-profit counterparts, as they have no incentives to increase their economic benefits. Hence, including private not-for-profit organizations in comparisons of public and private service production should diminish cost differences between the public and private sectors.

Summing up, the four main propositions derived from the theoretical expectations of the present study are as follows: (1) We cannot assume the existence of cost differences when comparing public and private service delivery; (2) When productive efficiency is the focus of a public versus private service-delivery comparison, the private sector tends to outperform the public sector. (3) By contrast, the public sector tends to perform better than the private sector when financial costs are the focus. (4) Studies that differentiate between private for-profit and private not-for-profit hospitals will find higher cost differences between public- and privatesector organizations.

\section{THE META-SAMPLE}

Table 1 presents the 21 studies used in this analysis, listing the number of estimators and observations each study contributed to the sample, country, and method. A total of 80 observations were included in the analysis. The studies were conducted in the US, Germany, 
Taiwan, Belgium, Spain, and Italy. The final sample of studies included in the meta-regression analysis is the result of several review stages, following standard procedures in meta-regression studies (see, for example, Bel \& Gradus 2016). In the initial stage, we identified studies of interest by reviewing papers published in the fields of Public Administration, Public Policy, Economics, and Health. To identify potentially suitable studies, we combined the keywords, "hospital performance" or "hospital efficiency" and "ownership," "public" or "private" and searched for them in the publication abstracts. The journals were reviewed by analyzing multiple databases, including Science Direct, Pubmed, Proquest, and JStor.

We also reviewed unpublished works archived in large working-paper collections, such as EconLit, the Social Science Network, and Repec-Ideas. Finally, we collected papers from databases specializing in $\mathrm{PhD}$ theses, including OpenGrey, the European Science Research Council (ESRC), the E Thesis Online Service (ETHOS), US GAO, and the National Technical Information Service (NTIS). Arguably, by the end of this stage, we had identified all studies of the influences of ownership on hospital performance. The database was built by the authors and the methodology is based on the MAER reporting guidelines in Stanley et al. (2013). The final search was concluded on 27 July 2018; it returned 19,303 results.

-- Insert Table 1 about here --

After the first search, we examined each study to determine whether it could be used to build the database. We initially found 31 studies that seemed well-suited for the metaregression. During the third and final stage, we carefully coded each identified paper to determine whether the author/s were addressing the effects of ownership on hospital performance empirically; we achieved this by distinguishing between the public and private sectors and the definitions of hospital performance used in each study. A fundamental characteristic of meta-regression studies is the fact that dependent variables drawn from 
selected studies must be very homogeneous to be compared; for this reason, we decided to exclude articles in which the dependent variables were too different from those included in the final sample (such as the performance of mental hospitals or dental care activities in Andersen \& Blegvad 2006; Jensen et al. 2009). Other studies were excluded because the reference categories in their estimations did not strictly compare public and private management, (i.e. Thorpe et al. 2001; Lien et al. 2008; Czypionka et al. 2014; Cavallieri et al. 2018; Cho \& Hong 2018). Other studies had to be excluded because the authors did not provide enough statistical information to include in the final database. In particular, publications that did not provide information on the T-statistics, standard errors, or p-values of their regressions could not be included, as it would have been impossible to compute the T-statistic (i.e. Goes \& Zhan 1995; Ferrier \& Valdmanis 1996; Connor, Feldman \& Dowd 1998). In all, 10 studies were excluded.

\section{THE META-REGRESSION}

Our final sample was derived from the 21 studies identified as containing homogeneous estimates of the performance of private relative to public production of hospital services. These studies included 96 estimations of hospital performance, according to the production form. Of these 96 estimations, 80 included all of the variables considered in this analysis, as well as homogeneous definitions of the production-form variable; these enabled us to obtain a t-value for the comparison between public and private production.

There are many reasons for the variation in t-values used to compare public and private production in empirical studies. Stanley and Jarrell (1989) have proposed three categories of factors: (1) the dataset employed in each study is unique; (2) the model specification may induce biases; and (3) the statistical methods employed are different. We have undertaken a meta-regression analysis to explain the diversity and pattern of findings in empirical studies. When constructing our data sample, we kept Stanley and Jarrell's (1989) points in mind. We 
have provided some technical details on the structure of the meta-regression model and the rationale for using t-values instead of coefficients as the dependent variable in the metaregression.

Most studies included in the sample used data on hospital costs to compare the financial performance of public and private hospitals. In several cases, the data reflected the technical efficiency of public and private hospitals (i.e. Chirikos \& Sear 1994; Sari 2003; Brown 2003; Tiemann \& Schreyögg 2009). When necessary, we transformed the T-statistics to ensure the homogeneity and robustness of the dependent variable in our meta-regression estimation (i.e. Chirikos \& Sear 1994).

We defined several moderator variables for the database. The first was a continuous variable, YearData, which reflected the year to which the study data belonged (or an average year, when data were obtained over several years). This variable was used to consider the possible existence of time trends affecting the comparative performance of public and private organizations. Such moderators are generally used in meta-regression analyses because they consider potential time effects. Some privatization articles have observed that older studies tend to give higher performance rankings to privately owned public services; however, this performance gap has diminished over the last few years (Bel et al. 2010).

Second, we included a set of moderator variables related to the characteristics of the model specification in each study. The second variable was the dummy variable, Panel, which took the value of one if a panel estimation method was used, and zero otherwise. This reflects the fact that panel estimations are richer in data and usually more robust than cross-section estimations. The third variable was the dummy variable, Individual, which took the value of one if the data collection took place at the individual (patient) level, and zero if the data 
collection took place at organizational (hospital) level. This variable allowed us to control for potential differences between microdata and organizational data.

Next, we included variables related to the exogenous characteristics of the study. Our fourth variable was a dummy variable, USA, which took the value of one if a study was conducted in the US, and zero otherwise; in this way, we acknowledged that the US does not have a universal system of health service provision, as is the case in all other countries for which studies in the data sample were conducted. Interestingly, there is some empirical evidence showing that the US has incurred higher costs when delivering health services than a comparable country with universal provision, such as Canada (Woolhandler et al. 2003). Furthermore, it is worth noting that $65 \%$ of the studies in our meta-regression were conducted in the US, so this variable helped to control for that fact. We also included a dummy variable for Germany, which took the value of one for Germany and zero otherwise, because four studies, conducted using data from German hospitals, provided more than $40 \%$ of the estimations. Together with this dummy, we used estimation techniques expressly designed to address the problem of correlation across observations.

Finally, we included our main independent variables. Our sixth variable was the dummy Not-for-profit (NFP), which took the value of one for estimations that included NFP alongside purely public and purely privately managed hospitals, and zero otherwise. Our last variable was the dummy variable, Cost, which took the value of one if the dependent variable in the estimation was cost-related, and zero otherwise (generally, in that case, productive efficiencyrelated indicators considered which inputs were necessary to obtain a certain output). It is important to remember that costs and productive efficiency are not strictly related in weakly competitive and heavily regulated sectors, such as this one. As a result, it is possible for productive units to be more efficient and to charge more for services at the same time (Vickers 
\& Yarrow, 1988, 1991), as shown in studies of the public and private delivery of public services, such as solid-waste collection (Bel \& Miralles 2010). Because the original estimations included both types of dependent variable — and these sometimes present the opposite sign to indicate superior performance-we were careful to make the signs homogeneous, ensuring that our meta-regression estimates would be robust.

Table 2 summarizes the dependent and independent variables used in this study, while Table 3 depicts the descriptive statistics for these variables, the dependent variable in the metaregression, and the variables used in the meta-regression tests.

-- Insert Table 2 about here-

-- Insert Table 3 about here --

In the meta-regression tests, to distinguish the true empirical effect from publication bias, we also use the reported standard error and t-statistics associated with the coefficient of the variable indicating production form in the regression equations, and the degrees of freedom. Note that this information was not available in all of the studies. Whenever the t-statistics were given, deriving the standard error was a straightforward task. When the degrees of freedom were not provided in the original studies, they could be calculated from the descriptive data by subtracting the number of regressors from the sample size. In the end, we obtained 80 observations for SE and their t-statistics.

The equation used to estimate the influence of different study characteristics on the comparison between public and private performance can be stated as follows:

$\mathrm{T}_{\mathrm{i}}=\alpha_{0}+\alpha_{1}$ YearData $_{\mathrm{i}}+\alpha_{2}$ Panel $_{\mathrm{i}}+\alpha_{3}$ Individual $_{\mathrm{i}}+\alpha_{4}$ USA $_{\mathrm{i}}+\alpha_{5}$ Germany $_{\mathrm{i}}+\alpha_{6}$ NFP $_{\mathrm{i}}+\alpha_{7}$ $P \operatorname{Cost}_{\mathrm{i}}+\varepsilon_{\mathrm{i}}$ 
where $T_{i}$ is the $t$-value reported in each estimation for the coefficient of the production form. When necessary, we homogenized the signs (according to the different specifications in the original models); the higher the value, the higher the cost (and the lower the efficiency) of private production. The moderator variables are as defined in the previous section (see also Table 2). We ran a formal test for the presence of multicollinearity and obtained a mean value of 2.78 for the variance inflation factor (VIF). All coefficients were below 6 , indicating that multicollinearity should not be a problem when interpreting the regression results (Damanpour \& Schneider 2009; Hair et al. 2006).

\section{RESULTS}

We estimated various meta-regression models to obtain robust results. First, we estimated an ordinary least squares (OLS) regression. We tested for heteroscedasticity and did not reject the hypothesis of constant variance, as we found that the Breusch-Pagan/Cook-Weisberg test had a value of 0.10 for the chi-square statistic, with a p-value of 0.318 . In addition, we included a robust OLS estimation to check the stability of our results. Results for both estimations are presented in Table 4.

Our sample consisted of observations obtained from 21 studies, each containing a different number of estimations, which can lead to the problem of dependence across observations (Nelson \& Kennedy 2009; Ringquist 2013). Other potential sources of dependence may exist across observations. One key source of dependence is the use of common datasets in different studies - as happens when ICMA data are used in several different articles assessing the choice of production modes of local public services in the US. However, it is worth noting that we did not have this problem in our analysis, as each database was unique to the study in which it was used. A second source of dependence across observations can occur when different studies are undertaken by the same research teams. In 
our sample, two studies conducted in Germany were carried out by the same scholars. However, as we included a variable to control for studies conducted in Germany, this was not a problem in our analysis.

To take full account of within-study autocorrelation, we followed the suggestion of Ringquist (2013, p. 218) and used generalized estimating equations (GEE) to estimate a random effects meta-regression model. In doing so, we clustered all of the estimations in each study to address the problem of dependence across observations. Another potential way of dealing with intra-study variability is to calculate a single average effect size from each original study, or to select the best estimation from among all estimations in a single study. We disregarded both of these approaches because they would have produced an extremely small sample (16 estimations) for our meta-analysis. As Nelson and Kennedy (2009) have warned and Ringqvist (2013) has also noted, this approach would have entailed discarding a large amount of information. It is worth noting that our robust GEE coefficients and signs were almost identical to those obtained when using a FGLS regression; the Wald chi-squared statistics obtained with GEE and FGLS were also similar, as shown in Table 4, which presents the results of the estimation of the meta-regression equation (1).

-- Insert Table 4 about here --

In relation to the variable that indicated potential time effects, all of the estimations showed no significance for YearData, suggesting that the time in which the study was conducted had no effect on the performance comparison of public and private production. Likewise, the variable Individual did not appear to be significant, in relation to relative performance. By contrast, the more robust studies, which used panel estimations, tended to 
find better performance under public production, as indicated by the positive and highly significant (always at the $1 \%$ level) sign for the variable Panel.

With respect to the countries in which studies were conducted, all of the estimations showed significance at the 5\% level for the US for better performance in public production, with the exception of the OLS robust. It is worth noting that our heteroscedasticity test suggested more robust results from OLS and GEE/GLS. In the same vein, studies conducted in Germany tended to find a highly significant (always at the $1 \%$ level but OLS robust) better level of performance in public production, as private production was associated with higher costs. We are not aware of specific data on cross-country differences in efficiency and productivity in the health sector; such data would indeed be useful to better understand these results. However, a possible explanation for the results can be found in the overall performance levels of the public sector in each country; these data are available at the Global Competitiveness Report (World Economic Forum), which evaluates and compares countries on (among many other issues) "(1.08) Efficiency of Government Spending” and "(1.09) Burden of Government Regulation." In the most recent published report (2017-2018), Germany and the US had a similar ranking in both aspects and were included among the best performing countries in the world. By contrast, Taiwan, and particularly Belgium, Spain, and Italy (the four remaining countries in our meta-regression) ranked much worse on both factors. So, when our results showed that the German and US public sectors outperformed the private sector in health to a greater extent than those of the remaining countries in our study, this finding was consistent with available comparative data on the overall efficiency of the public sector in countries included in the present study. 
The meta-regression gave a strong indication that studies conducted in the US and Germany, which used financial data and conducted panel estimations, associated better performance with public production.

Turning to the moderator variables related to theoretical insights, we found that not-forprofit management did not have a significant relationship with the relative performance of production forms, as Not-for-Profit coefficients did not have statistical significance. Instead, studies that used financial data to analyze costs tended to find better performance within public production, as the sign for the variable Cost was positive and highly significant (always at the $1 \%$ level). These results challenged the fourth theoretical proposition presented earlier in this study, in which we expected to find that not-for-profit organizations delivering public services incurred higher costs than their for-profit counterparts, since they lacked incentives to increase their economic benefits.

Our meta-regression included two articles (Augurzki et al. 2012, and Langaber et al. 2018), which analyzed the effect of the form of production on the probability that a hospital would experience financial default. As there might be not enough homogeneity within the dependent variables in the other 19 studies, we needed to check the stability of our results. By excluding these two articles, we again obtained OLS, GEE and GLS estimates, this time with 19 studies including 76 raw estimations. The results were identical - signs and significance for all variables in the model. These results are available upon request.

\section{ROBUSTNESS TESTS}

Identifying potential publication bias is a major concern of any meta-regression model. Studies that find statistically significant relationships between variables of interest are arguably more likely to be published in top academic journals, leading to incorrect conclusions on the effectiveness of particular types of hospital ownership. A priori, we did not believe that 
publication bias would be a serious problem in the present analysis, mainly because there was no unanimously accepted theoretical view on the relative performance of public and private production in the management of health services. Indeed, most studies analyzed the dimensions of the effect, rather than its existence.

Nonetheless, as publication bias could upwardly bias the effectiveness of an organization's ownership, it was important to deal with this potential problem. Stanley and Doucouliagos (2012) have developed funnel asymmetry tests (FATs) to identify and correct for possible publication bias. These tests estimate the relationship between a study's reported t-statistics on the one hand, and the SE of its coefficients and the sample size of the estimation on the other. This can be stated in the following equations:

$$
\begin{gathered}
T_{i}=\beta_{0}+\beta_{1}\left(\frac{1}{S E_{i}}\right)+\varepsilon_{i} \\
T_{i}=\beta_{0}+\beta_{1} S Q R \_ \text {SampleSizei }+\varepsilon_{i}
\end{gathered}
$$

where $T$ is a study's reported t-statistic, $1 / \mathrm{SE}$ is the inverse of the standard error (Inverse_StandardErrors), and SQR_SampleSize is the Square Root of the sample size.

Evidence of publication bias will be found when $\beta_{0} \neq 0$. Equations (2) and (3) are included in Table 5.

Additionally, in line with Stanley (2008), we also conducted a meta-significance test (MST) to test the true empirical effect, using the following equation:

$$
\log \left|T_{i}\right|=\gamma_{0}+\gamma_{1} \log \left(d f_{i}\right)+\varepsilon_{i}
$$

where $d f$ are the degrees of freedom of the estimate reported [and $\log (\mathrm{df})$ is the logarithm of degrees of freedom]. The MST is based on the statistical property that the dimension of the $\mathrm{t}-$ statistic will vary systematically with the degrees of freedom if there is a genuine empirical 
effect (Stanley 2008). Therefore, Stanley (Ibid.) argues that if $\gamma_{1}=0$, the true effect is disputable. These results are included in Table 5.

\section{-- Insert Table 5 about here --}

It is important to note that the FAT estimates the relationship between a study's reported effect and its coefficients' standard errors, or sample size. An intercept significantly different from zero (Ibid.) provides evidence of publication bias. The results of our FAT, presented in Table 5, confirm the hypothesis of no publication bias because the intercept is not statistically different from zero in any case.

We did not initially find evidence of the existence of a "true" effect or genuine empirical effect in the FAT. However, the results of the MST show that the coefficient of Logdf was positive and highly statistically significant, indicating better performance with public production. Performance therefore seems to be better in public hospitals, based on the MST result, although some caution is needed because no true effect was obtained from the FAT.

\section{CONCLUSION}

Studies comparing the performance of public and private organizations have generated robust findings over the last few decades (see, among others, Boyne 1998, 2002; Hodge 2000; Bel \& Warner 2008; Bel et al. 2010; Basu et al. 2012). Despite this, the results of the present metaregression offer some important insights for those interested in the costs and efficiency of public and private hospitals. First, studies of German and US hospitals found that private hospitals performed worse than their public counterparts. This finding is of particular interest because these two countries have very different types of health sectors. Nevertheless, we see that German and US hospitals have a stronger association with better public performance than hospitals in other countries. Second, studies that rely on panel data tend to find that public 
hospitals outperform private ones. Arguably, when more robust methodologies are applied, such as panel data approaches, the results present a more favorable cost performance for public hospitals than when they rely on cross-sectional analyses. Third, the use of financial cost data tends to be associated with better performance by public hospitals. Finally, including not-forprofit hospitals when analyzing public and private sector differences does not seem to produce any effect. When we distinguish between private for-profit and private not-for-profit in the public/private comparison, the results do not change.

Our results from the FAT estimations do not allow us to claim a true empirical effect of ownership on costs and efficiency, meaning that no systematic differences exist between public and private production. However, it is worth noting that our MST suggests that public hospitals outperform private ones. Future research is needed to better understand whether ownership has a true effect on organizational performance when contextual and organizational variables are controlled for. The present study is limited by the number of estimators included in the hospital-performance literature. A common critique of meta-regression studies is that they do not allow for a fine comparison of how each dependent and independent variable in every study in the sample has been measured (Borestein et al. 2009). While the present study prioritized the use of similar measures over the $n$ of our sample, future studies should look at other performance information to further explore the effects of ownership on organizational outputs and outcomes.

To conclude, the evidence provided by this meta-regression lends some empirical support for the dimensional or "publicness approach" referred to by Bozeman and Bretschneider (1994), as it shows that the distinction between public and private does not explain clear performance differences per se; instead, we must consider a large array of environmental and organizational characteristics to understand why performance differences 
occur across sectors. More than two decades ago, Perry and Rainey (1988) warned that articles on public/private differentiation tended to represent the distinction using a categorical variable for either public or private. After reviewing the literature, these authors proposed that organization type be defined using a cross-classification of three variables: ownership, funding, and mode of social control. However, despite this attempt at classification, most (if not all) of the studies that compare public and private organizations have relied on ownership alone to distinguish between public and private entities (Bozeman 1987; Perry \& Rainey 1988; Boyne 2002). The present analysis demonstrates that any comparison of public and private performance requires a broader theoretical framing, which includes several moderating factors. Only by developing further research on these moderators of ownership and organizational performance will we be able to distinguish when and how private organizations are likely to offer a better option for the delivery of health services. This means achieving the best of both worlds: developing organizational forms that increase the productive efficiency of the service, without increasing its financial costs.

\section{APPENDIX}

The standard econometric model has the following structure:

$$
Y=X \beta+\varepsilon
$$

This allows for an explanation of the determinants of an event, and their magnitude and relevance. Now, in order to explain reported differences, Jarrell and Stanley (1989) have proposed the following structure for a model to synthesize the various findings:

$$
b_{j}=\beta+\sum \alpha_{k} Z_{j k}+e_{j},{ }_{k=1}^{K}(j=1,2, \ldots L)
$$

Where $b_{j}$ (observed dependent variable) is the reported coefficient of the true effect $-\beta$ from the $j$ th study of the set of estimations from the studies included in the database. The right side 
of the equation displays the "meta-part." $\alpha_{k}$ stands for the meta-regression coefficients, $Z_{j k}$ for meta-independent variables that capture systematic differences between observations, and $e_{j}$ is the meta-regression disturbance term. In practice, for $b_{j}$, it is customary to use the ratio between the coefficient and the standard error (the t-value) rather than the reported coefficients. The main reason for this is that, in studies using different datasets, sample sizes, and specifications, the variances of the coefficients are likely to be different; this can make the meta-regression errors heteroscedastic.

\section{REFERENCES}

Andersen L. B. and Blegvad M. 2006. "Does Ownership Matter for the Delivery of Professionalized Public Services? Cost-Efficiency and Effectiveness in Private and Public Dental Care for Children in Denmark." Public Administration 84(1): 147-64.

Augurzky, B., Engel, D. Schmidt, C.M. and Schwierz, C. 2012. "Ownership and Financial Sustainability of German Acute Care Hospitals.” Health Economics 21 (7): 811-824.

Andrews R., Boyne G. A., Meier K. J., O’Toole L. J. and Walker R. M. 2012. "Vertical Strategic Alignment and Public Service Performance.” Public Administration 90(1): 77-98.

Andrews R., Boyne G. A. and Walker R. M. 2011. "Dimensions of Publicness and Organizational Performance: A Review of the Evidence.” Journal of Public Administration Research \& Theory 21(suppl_3): i301-i319.

Basu S., Andrews J., Kishore S., Panjabi R. and Stuckler D. 2012. "Comparative Performance of Private and Public Healthcare Systems in Low- and Middle-Income Countries: A Systematic Review.” PLoS Med 9: e1001244. 
Bel G., Fageda X. and Warner M. E. 2010. "Is Private Production of Public Services Cheaper Than Public Production? A Meta-Regression Analysis of Solid Waste and Water Services." Journal of Policy Analysis and Management 29(3): 553-577.

Bel G. and Gradus R. 2016. "Effects of Unit-Based Pricing on Household Waste Collection Demand: A Meta-regression Analysis.” Resource and Energy Economics 44(1): 16-9182.

Bel, G. and Miralles A. 2010. "Choosing between service fees and budget funding to pay for local services: Empirical evidence from Spain.” Environment and Planning C: Government \& Policy 28(1): 54-71.

Bel G. and Warner M. 2008. "Does Privatization of Solid Waste and Water Services Reduce Costs? A Review of Empirical Studies." Resources, Conservation and Recycling 52(12):1337-1348.

Borenstein M., Hedges L. V., Higgins J. P. and Rothstein H. R. 2009. Introduction to MetaAnalysis. Chichester, UK: Wiley.

Bosmans N. and Fecher F. 1995. "Performance of Belgian Hospitals: A Frontier Approach." Health Economics 4(5): 389-397.

Box R. C. 1999. "Running Government like a Business." American Review of Public Administration 29(1): 1-19.

Boyne G. A. 1998. "Bureaucratic Theory Meets Reality: Public Choice and Service Contracting in US Local Government.” Public Administration Review 58(6): 474-484.

Boyne G. A. 2002. "Public and Private Management: What's the Difference?" Journal of Management Studies 39(1): 97-122. 
Boyne, G. A., Farrell, C., Law, J., Powell, M. and Walker, R. M. 2003. Evaluating Public Management Reforms: Principles and Practice. Philadelphia and Buckingham: The Open University Press.

Bozeman, B. and Bretschneider S. 1994. “The 'Publicness Puzzle' in Organization Theory: A Test of Alternative Explanations of Differences between Public and Private Organizations." Journal of Public Administration Research and Theory 4(2): 197-224.

Brown H. S. 2003. "Managed Care and Technical Efficiency.” Health Economics 12(2): 149158.

Campbell, E. S. 1990. "Hospital Efficiency and Indigent Care.” Applied Economics 22(11): $1597-1610$.

Carey K. 1997. “A Panel Data Design for Estimation of Hospital Cost Functions.” Review of Economics and Statistics 79 (3): 443-453.

Carvalho P. R., Marques C. and Berg S. 2012. “A Meta-regression Analysis of Benchmarking Studies on Water Utilities Market Structure.” Utilities Policy 21(2): 40-49.

Cavalleri M., Guccio C., Lisi D. and Pignataro G. 2018. "Does the Extent of per Case Payment System Affect Hospital Efficiency? Evidence from the Italian NHS." Public Finance Review 46(1): 117-149.

Chandler J. A. 1991. "Public Administration and Private Management. Is there a Difference?" Public Administration 69(3): 385-392.

Chirikos T. N. and Sear A. M. 1994. "Technical Efficiency and the Competitive Behaviour of Hospitals.” Socio-Economic Planning 28(4): 219-227. 
Cho N. and Hong K. 2018. "A Kitchen with too Many Cooks: Factors Associated with Hospital Profitability." Sustainability 10(2): 323.

Collins J. N. and Downes B. T. 1977. "The Effect of Size on Provision of Public Services the Case of Solid Waste Collection in Smaller Cities." Urban Affairs Quarterly 12(3): 333-47.

Connor R. A., Feldman R. D. and Dowd B. E. 1998. "The Effects of Market Concentration and Horizontal Mergers on Hospital Costs and Prices.” International Journal of the Economics of Business 5(2): 159-180.

Czypionka T., Kraus M., Mayer S. and Röhrling G. 2014. "Efficiency, ownership, and financing of hospitals: The case of Austria." Health Care Management Science 17(4): $331-347$.

Damanpour F. and Schneider M. 2009. "Characteristics of Innovation and Innovation Adoption in Public Organizations: Assessing the Role of Managers." Journal of Public Administration Research and Theory 19(3): 495-522.

Ding D. X. 2014. "The Effect of Experience, Ownership and Focus on Productive Efficiency: A Longitudinal Study of U.S. Hospitals.” Journal of Operations Management 32(1-2): 114.

Fageda X. and Fiz E. 2011. Ownership, Incentives and Hospitals. Fundación de las Cajas de Ahorro. Documento de Trabajo ${ }^{\circ}$ 591/2011.

Ferrier G. D. and Valdmanis V. 1996. "Rural Hospital Performance and Its Correlates." Journal of Productivity Analysis 7(1): 63-88.

Fournier G. M. and Mitchell J. M. 1997. "New Evidence on the Performance Advantages of Multihospital Systems.” Review of Industrial Organization 12(5/6): 703-718. 
Goes J. B. and Zhan C. 1995. "The Effects of Hospital-Physician Integration Strategies on Hospital Financial Performance.” HSR: Health Services Research 30(4): 507-530.

Goddard, M. 2015. "Competition in Healthcare: Good, Bad or Ugly?" International Journal of Health Policy and Management, 4(9): 567-569.

Gray B. H. 1986. For-Profit Enterprise in Health Care. Institute of Medicine. National Academy Press, Washington DC.

Guerrini A., Romano G., Campedelli B., Moggi S. and Leardini C. 2018. "Public vs. Private in Hospital Efficiency: Exploring Determinants in a Competitive Environment." International Journal of Public Administration, 41(3): 181-189,

Hair J. F., Anderson E. R., Tatham R. L. and Black W. C. 2006. Multivariate Data Analysis. Upper Saddle River, NJ: Prentice Hall.

Haque M. S. 2001. "The Diminishing Publicness of Public Service Under the Current Mode of Governance." Public Administration Review, 61: 65-82.

Hefetz A. and Warner M. E. 2012. "Contracting or Public Delivery? The Importance of Service, Market, and Management Characteristics." Journal of Public Administration Research and Theory 22(2): 289-317.

Herr A. 2008. "Cost and Technical Efficiency of German Hospitals: Does Ownership Matter?“ Health Economics 17(9): 1057-1071.

Herr A., Schmitz H. and Augurzky B. 2011. "Profit Efficiency and Ownership of German Hospitals." Health Economics 20(6): 660-674.

Hirsch W. Z. 1995. "Contracting Out by Urban Governments: A Review.” Urban Affairs Review 30(3): 458-472. 
Hodge G. 2000. Privatization: An International Review of Performance. Boulder, CO: Westview Press.

Jensen P. H., Webster E. and Witt J. 2009. "Hospital Type and Patient Outcomes: An Empirical Examination Using AMI Readmission and Mortality Records." Health Economics 18(12): $1440-1460$.

Jiang J. H., Friedman B. and Begun J. W. 2006. "Factors Associated with High- Quality/LowCost Hospital Performance." Journal of Health Care Finance 32(3): 39-52.

Kay J. A. and Thompson D. J. 1986. Privatization: A Policy in Search of a Rationale. The Economic Journal, 96: 18-32.

Kemper P. and Quigley J. 1976. The Economics of Refuse Collection. Cambridge (MA): Ballinger.

Kessler P. D. and McClellan M. B. 2002. "The Effects of Hospital Ownership on Medical Productivity." The RAND Journal of Economics 33(3): 488-506.

Kitchen H. M. 1976. “A Statistical Estimation of an Operating Cost Function for Municipal Refuse Collection.” Public Finance Quarterly 4(1):56-76.

Langabeer II, J. R., Lalani K. H., Champagne-Langabeer T. and Helton J. R. 2018. "Predicting Financial Distress in Acute Care Hospitals." Hospital Topics, DOI: $\underline{10.1080 / 00185868.2018 .1451262}$

Lien H. M., Chou, S. Y. and Liu, J. T. 2008. "Hospital ownership and performance: evidence from stroke and cardiac treatment in Taiwan." Journal of Health Economics 27/5: 10281223.

Lin H., Kao S., Wen H., Wu C. and Chung C. 2005. "Length of Stay and Costs for Asthma Patients by Hospital Characteristics-A Five-Year Population-Based Analysis." Journal of Asthma 42(7): 537-542. 
Murray M. A. 1975. "Comparing Public and Private Management: An Exploratory Essay." Public Administration Review 35(4): 364-371.

Nelson J. P. and Kennedy P. E. 2009. "The Use (and Abuse) of Meta-analysis in Environmental and Natural Resource Economics: An Assessment." Environmental and Resource Economics 42(3): $345-377$.

Nutt P. 1993. "Organizational Publicness and Its Implications for Strategic Management." Journal of Public Administration Research and Theory 3(2): 209-231.

Perry J. L. and Rainey H. G. 1988. "The Public-Private Distinction in Organization Theory: A Critique and Research Strategy." Academy of Management Review 13(2): 182-201.

Pesch U. 2008. "The Publicness of Public Administration." Administration \& Society 40(2): $170-193$.

Petersen O. H., Hjelmar U. and Vrangbæk K. 2018. "Is Contracting out of Public Services still the Great Panacea? A Systematic Review of Studies on Economic and Quality Effects from 2000 to 2014." Social Policy \& Administration 52(1): 130-157.

Pollitt C. and Bouckaert G. 2011. Public Management Reform: A Comparative Analysis. New Public Management, Governance and the Neo-Weberian State. Oxford: Oxford University Press.

Pommerehne W. W. and Frey B. 1977. "Public Versus Private Production Efficiency in Switzerland: A Theoretical and Empirical Comparison.” In: Ostrom V., Pendell R. B., editors. 1977. Comparing Urban Service Delivery Systems. Urban Affairs Annual Review 12: $221-41$.

Productivity Commission 2009. Public and Private Hospitals, Research Report. Canberra: Australian Government Productivity Commission. 
Ring P. S. and Perry J. L. 1985. "Strategic Management in Public and Private Organizations: Implications of Distinctive Contexts and Constraints." Academy of Management Review 10(2): 276-286.

Ringquist E. J. 2013. Meta-analysis for Public Management and Policy. Jossey-Bass, Wiley \& Sons. San Francisco, CA.

Rosenau P. V. and Linder S. H. 2003. “Two Decades of Research Comparing For-Profit and Nonprofit Health Provider Performance in the United States." Social Science Quarterly 84(2): 219-241.

Rosko M. D. 1999. "Impact of Internal and External Environmental Pressures on Hospital Inefficiency.” Health Care Management Science 2(2): 63-74.

Rosko M. D. 2004. "Performance of U.S. Teaching Hospitals: A Panel Analysis of Cost Inefficiency." Health Care Management Science 7(1): 7-16.

Sari N. 2003. "Efficiency Outcomes of Market Concentration and Managed Care." International Journal of Industrial Organization 21(10): 1571-1589.

Scott P. G. and Falcone S. 1998. "Comparing Public and Private Organizations - An Exploratory Analysis of Three Frameworks." American Review of Public Administration 28(2): 126-145.

Stanley T. D. 2008. "Meta-Regression Methods for Detecting and Estimating Empirical Effect in the Presence of Publication Bias." Oxford Bulletin of Economics and Statistics 70(1): 103127.

Stanley T. D. and Doucouliagos H. 2012. Meta-Regression Analysis in Business and Economics. Routledge Advance in Research Methods. Routledge, Oxon. 
Stanley T. D., Doucouliagos H., Giles M., Heckemeyer J. H., Johnston R. J., Laroche P., Nelson J. P., Paldam M., Poot J., Pugh G., Rosenberger R. S. and Rost K. 2013. "MetaAnalysis of Economics Research Reporting Guidelines." Journal of Economic Surveys 27(2): 390-394.

Stanley T. D. and Jarrell S. B. 1989. "Meta-regression Analysis: A Quantitative Method of Literature Surveys.” Journal of Economic Surveys 3(2): 54-67.

Stiglitz J. E. 2000. Economics of the Public Sector. WW. Norton.

Tiemann O. and Schreyögg J. 2009. "Effects of Ownership on Hospital Efficiency in Germany.” Business Research 2(2): 115-145.

Thorpe K. E., Seiber E. E. and Florence C. S. 2001. "The Impact of HMOs on Hospital-Based Uncompensated Care.” Journal of Health Politics, Policy and Law 26(3): 543-555.

Vickers J. and Yarrow G. 1988. Privatization: An Economic Analysis. Cambridge, MA: MIT Press.

Vickers J. and Yarrow G. 1991. "Economic Perspectives on Privatization.” Journal of Economic Perspectives 5(2): 111-132.

Vitalino T. F. and Toren M. 1996. "Hospital Cost and Efficiency in a Regime of Stringent Regulation.” Eastern Economic Journal 22(2): 161-175.

Walker R. M., Brewer G. A., Bozeman B., Moon M. J. and Wu J. 2013. “An Experimental Assessment of Public Ownership and Performance." Public Management Review 15(8): $1208-1228$. 
Woolhandler S., Campbell T. and Himmelstein D. H. 2003. "Costs of Health Care Administration in the United States and Canada." New England Journal of Medicine 349(8): $768-775$.

WEF. 2017. "The Global Competitiveness Report 2017-2018." World Economic Forum, Geneva. 


\section{TABLES}

Table 1. Main characteristics-multivariate studies comparing performance in the public and private provision of health services

\begin{tabular}{|lccccc|}
\hline \multicolumn{1}{|c}{ Authors } & $\begin{array}{c}\text { Number of } \\
\text { Estimations }\end{array}$ & $\begin{array}{c}\text { Year } \\
\text { Sample }\end{array}$ & Sample & Country & Method* \\
\hline Campbell (1990) & 3 & 1986 & 224 & USA & OLS \\
Chirikos \& Sear (1994) & 3 & 1989 & 189 & USA & OLS \\
Bosmans \& Fecher (1995) & 1 & 1991 & 150 & Belgium & OLS \\
Vitaliano \& Toren (1996) & 1 & 1991 & 219 & USA & OLS \\
Fournier \& Mitchell (1997) & 1 & $1984-1986$ & 534 & USA & SUR \\
Carey (1997) & 5 & $1987-1991$ & 1733 & USA & OLS \\
Rosko (1999) & 3 & 1994 & 3262 & USA & OLS \\
Kessler \& McLellan (2002) & 1 & $1985-1996$ & 1661674 & USA & OLS \\
Brown (2003) & 5 & $1992-1996$ & 1907 & USA & OLS \\
Sari (2003) & 5 & $1994-1998$ & 876 & USA & OLS \& Panel \\
Rosko (2004) & 2 & $1990-1999$ & 407 & USA & Panel \\
Lin et al. (2005) & 1 & $1997-2001$ & 139630 & Taiwan & OLS \\
Jiang (2006) & 2 & $1997-2001$ & 1369 & USA & Logistic \\
Herr (2008) & 10 & $2001-2003$ & 1665 & Germany & OLS \& Panel \\
Tiemann \& Schreyögg (2009) & 11 & $2002-2006$ & 4902 & Germany & Panel \\
Fageda \& Fiz (2011) & 2 & $1997 \& 2007$ & 1275 & Spain & OLS \\
Herr, Schmitz \& Augurzky (2011) & 10 & $2002-2006$ & 1579 & Germany & OLS \\
Augurzki et al. (2012) & 3 & $2001-2005$ & 962 & Germany & OLS \& PANEL \\
Ding (2014) & 8 & 2003 & 50916 & USA & OLS \\
Guerrini et al. (2017) & 2 & $2011-2012$ & 142 & Italy & Tobit \& OLS \\
Langaber et al. (2018) & 1 & $2012-2015$ & 1240 & USA & OLS \\
\hline
\end{tabular}

* OLS \& Panel indicates that some regressions use OLS and others Panels in the same study. 
Table 2. Definition of variables

Dependent variable

$t$-value $\quad \mathrm{t}$-value of the production form in the estimations

Moderator variables

Year Data $\quad$ were obtained

Continuous variable that reflects the year(s) for which the data

Panel Dummy with one if the study used panel estimation method

Individual Dummy with one if data were obtained for patients

USA Dummy with one if the study was conducted in USA

Germany Dummy with one if the study was conducted in Germany

Not-For-Profit Dummy with one if the study included Not-For-Profit hospitals

Cost Dummy with one if the study measured financial costs

Table 3. Descriptive statistics of variables used in meta-regression analysis and metaregression tests

\begin{tabular}{llllll} 
& Average & SD & Max & Min & $\mathrm{N}^{\mathbf{2}}$ \\
\hline t-Statistic & 0.94 & 8.43 & 39.77 & -38.40 & 80 \\
Year Data & 1999.08 & 6.54 & 2015 & 1984 & 80 \\
Panel & 0.35 & 0.48 & 1.00 & 0.00 & 80 \\
Individual & 0.01 & 0.11 & 1.00 & 0.00 & 80 \\
USA & 0.50 & 0.50 & 1.00 & 0.00 & 80 \\
Germany & 0.43 & 0.50 & 1.00 & 0.00 & 80 \\
Not-for-Profit & 0.70 & 0.46 & 1.00 & 0.00 & 80 \\
Cost & 0.63 & 0.49 & 1.00 & 0.00 & 80 \\
Standard error & 2.82 & 19.99 & 178.98 & 0.00 & 80 \\
Degrees of freedom & 29392 & 186019 & 1661669 & 135 & 80 \\
\hline
\end{tabular}


Table 4. Meta-regression estimates (OLS, Robust OLS, GEE, and GLS)

\begin{tabular}{|l|l|l|l|l|}
\hline & \multicolumn{1}{|c|}{ OLS } & \multicolumn{1}{c|}{ OLS } & \multicolumn{1}{c|}{ GEE } & \multicolumn{1}{c|}{ FGLS } \\
\hline Year Data & -0.134 & -0.134 & -0.140 & -0.134 \\
& $(0.163)$ & $(0.117)$ & $(0.174)$ & $(0.146)$ \\
\hline Panel & $9.288^{* * *}$ & $9.288^{* * *}$ & $8.492^{* * *}$ & $9.288^{* * *}$ \\
& $(2.221)$ & $(2.478)$ & $(2.330)$ & $(2.107)$ \\
\hline Individual & -9.039 & -9.039 & -7.842 & $-9.039^{*}$ \\
& $(5.242)$ & $(16.770)$ & $(5.187)$ & $(4.973)$ \\
\hline USA & $8.072^{* *}$ & 8.072 & $10.076^{* *}$ & $8.072^{* *}$ \\
& $(3.744)$ & $(5.298)$ & $(3.979)$ & $(3.551)$ \\
\hline Germany & $9.483^{* * *}$ & $9.483^{*}$ & $11.206^{* * *}$ & $9.483^{* * *}$ \\
& $(3.439)$ & $(4.842)$ & $(3.971)$ & $(3.262)$ \\
\hline Not-For-Profit & -0.181 & -0.181 & -1.894 & -0.181 \\
& $(1.989)$ & $(2.038)$ & $(5.430)$ & $(1.887)$ \\
\hline Cost & $6.417 * * *$ & $6.417 * *$ & $5.804 * * *$ & $6.417 * * *$ \\
& $(1.872)$ & $(2.503)$ & $(2.090)$ & $(1.776)$ \\
\hline Constant & 254.683 & 254.683 & 255.577 & 254.683 \\
& $(307.326)$ & $(234.989)$ & $(347.776)$ & $(291.555)$ \\
\hline $\mathrm{N}$ & 80 & 80 & 80 & 80 \\
\hline $\mathrm{F}$ & $7.96^{* * *}$ & $3.90^{* * *}$ & & \\
\hline R2 & 0.4363 & 0.4363 & & \\
\hline Breusch-Pagan/Cook- & 0.318 & & & \\
Weisberg test (p>chi2) & & & & \\
\hline VIF & 2.78 & & 46.82 & 61.92 \\
\hline Wald(chi)2 & & & $0.000^{* * * *}$ & $0.000^{* * * *}$ \\
\hline Prob > chi2 & & &
\end{tabular}

Level of significance: $*=10$ per cent $; * *=5$ per cent $; * * *=1$ per cent

Table 5. Meta-regression tests: Funnel Asymmetry [FAT (1), FAT (2)(Robust)] and Meta-Significance [MST(Robust)]

\begin{tabular}{l|c|c|c}
\hline Explanatory variables & $\begin{array}{c}\text { FAT I test } \\
\text { Dep. Variable t- } \\
\text { Statistic }\end{array}$ & $\begin{array}{c}\text { FAT II test } \\
\text { Dep. Variable t- } \\
\text { Statistic }\end{array}$ & $\begin{array}{c}\text { MST: } \\
\text { Dep. Variable: log (t- } \\
\text { Statistic in Absolute } \\
\text { Values) }\end{array}$ \\
\hline Invers_StandardErrors & -0.0025 & --- & --- \\
SQR_SampleSize & $(0.0147)$ & 0.004 & \\
Log(DegreesFreedom) & --- & $(0.009)$ & $0.332^{* * *}$ \\
Constant & --- & -- & $(0.117)$ \\
$\mathrm{R}^{2}$ & 1.308 & 0.626 & $-0.932^{* * *}$ \\
$\mathrm{~F}$ & $(0.956)$ & $(0.939)$ & $(0.428)$ \\
$\mathrm{N}$ & 0.0364 & 0,0053 & 0.0902 \\
& 2.95 & 0.20 & $8.06^{* * *}$ \\
\hline
\end{tabular}

Level of significance: $* *=5$ per cent $; * * *=1$ per cent 